\title{
Possible Influence of Volcanic Activity on the Decadal Potential Predictability of the Natural Variability in Near-Term Climate Predictions
}

\author{
Hideo Shiogama, ${ }^{1}$ Seita Emori, ${ }^{1,2}$ Takashi Mochizuki, ${ }^{3}$ Sayaka Yasunaka, ${ }^{2}$ Tokuta Yokohata, ${ }^{3}$ \\ Masayoshi Ishii, ${ }^{4}$ Toru Nozawa, ${ }^{1}$ and Masahide Kimoto ${ }^{2}$ \\ ${ }^{1}$ National Institute for Environmental Studies, 22-1 Onogawa, Tsukuba, Ibaraki 305-8506, Japan \\ ${ }^{2}$ Center for Climate System Research, University of Tokyo, 5-1-5 Kashiwanoha, Kashiwa, Chiba 277-8568, Japan \\ ${ }^{3}$ Japan Agency for Marine-Earth Science and Technology, 3173-25 Showamachi, Kanazawa-ku, Yokohama, Kanagawa 236-0001, Japan \\ ${ }^{4}$ Meteorological Research Institute, 1-1 Nagamine, Tsukuba, Ibaraki 305-0052, Japan
}

Correspondence should be addressed to Hideo Shiogama, shiogama.hideo@nies.go.jp

Received 23 March 2010; Accepted 7 June 2010

Academic Editor: Eugene Rozanov

Copyright ( $) 2010$ Hideo Shiogama et al. This is an open access article distributed under the Creative Commons Attribution License, which permits unrestricted use, distribution, and reproduction in any medium, provided the original work is properly cited.

Initialization based on data assimilations using historical observations possibly improves near-term climate predictions. Significant volcanic activity in the future is unpredictable and not assumed in future climate predictions. To examine the possible influence of unpredictable future volcanic activity on the decadal potential predictability of the natural variability, we performed a 20062035 climate prediction experiment with the assumption that the 1991 Mt. Pinatubo eruption would take place again in 2010. The Pinatubo forcing induced not only significant cooling responses but also considerable noises in the natural variability. The errors due to the Pinatubo forcing grew faster than that arising from imperfect knowledge of the observed state, leading to a rapid reduction of the decadal potential predictability of the natural variability.

\section{Introduction}

Near-term climate predictions up to the year 2035 are useful for adaptation to the possible consequences of rapid climate changes and will be highlighted in the next assessment report of the Intergovernmental Panel on Climate Change (IPCC) [1-5]. Near-term predictions could be significantly affected by the natural variability [3,6-9]. Our previous studies $[10,11]$ addressed the issues of signal-to-noise ratios of temperature extremes, annual mean precipitation, and extreme precipitation in near-term predictions. Furthermore, climate modeling centers are now exploring the possibility that an initialization based on assimilations of observed historical data assists in the prediction of the decadal natural variability in near-term predictions $[9,12-21]$.

In general, climate predictions are performed under scenarios of greenhouse gas concentrations and anthropogenic aerosol emissions. Natural external forcing factors, such as changes in solar irradiance and volcanic activity, are not generally considered, since future changes in solar irradiance are unclear and volcanic activity is unpredictable. However, large volcanic activity may occur in the upcoming decades [22]. By including the stochastic fluctuations of natural external factors based on historical forcing, Bertrand et al. [23] examined the potential influences of natural external forcing factors. They suggested that natural external forcing might exert significant influences on anthropogenic global warming in the coming decades.

Significant volcanic activity would reduce the global mean temperature for several years [24]. Volcanically induced cooling at the surface could penetrate into deeper oceans, where it might persist for decades [25-27]. It has been suggested that volcanic activity affects the interannual natural variabilities $[24,28,29]$. On the other hand, few studies have investigated effects of volcanic forcing on the decadal natural variability. Volcanically induced cooling in 


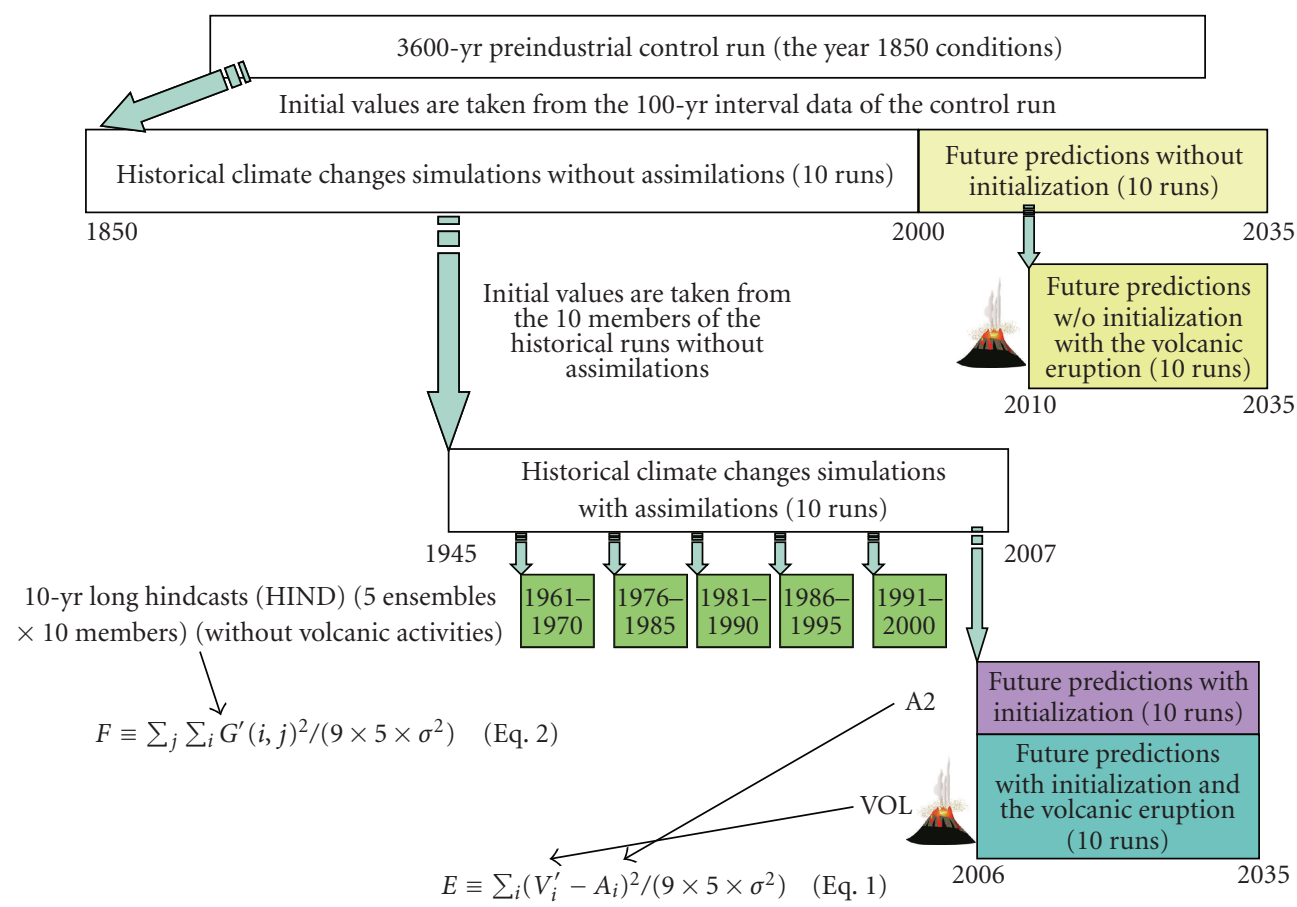

FIgURE 1: The experimental set-up.

oceans may also reduce the predictability of the decadal natural variability. The aim of this study was to determine whether the decadal predictability of the natural variability could persist in spite of disturbances due to a large volcanic eruption. To address this issue, we performed and analyzed climate simulations of a coupled atmosphere-ocean general circulation model (AOGCM) with and without volcanic forcing.

\section{Simulations and Methods}

We used the MIROC3 AOGCM [30] for our simulations. The spatial resolution of the atmospheric component is T42 with 20 vertical levels (the height of the model top is approximately $30 \mathrm{~km}$ ), while the horizontal resolution of the ocean component is $1.4^{\circ}$ in longitude by a variable $0.56-1.4^{\circ}$ in latitude with 44 vertical levels (21 levels in the upper $500 \mathrm{~m}$ ). This model requires no flux adjustment. To implement volcanic forcing, we simply incorporate a variation in the stratospheric aerosol optical thickness at $0.55 \mu \mathrm{m}$ in the radiation code. It has been shown that this model can reproduce the observed climate cooling after a significant volcanic eruption $[31,32]$.

We performed two ensembles of climate predictions for the 2006-2035 period with and without significant volcanic activity; we refer to these as VOL and A2, respectively (Figure 1). Both VOL and A2 were forced by anthropogenic changes in well-mixed greenhouse gases, aerosols, and ozone under the SRES A2 scenario [33]. The difference between VOL and A2 is that VOL includes, after June 2010, a variation in the stratospheric aerosol optical thickness at $0.55 \mu \mathrm{m}$, as occurred following the June 1991 eruptions of Mt. Pinatubo, Philippines [34]. This design of the predictions with 2010 Pinatubo-like eruption was proposed as a part of the Coupled Model Intercomparison Project Phase 5 (http://cmip-pcmdi.llnl.gov/cmip5/). Each ensemble consisted of 10 runs. The initial conditions of VOL and A2 on 1st January 2006 were taken from a 10-member ensemble of 1945-2007 assimilation (Figure 1). The methodology of the initialization based on the assimilation was basically the same as that of Mochizuki et al. [21] with slight modifications: we assimilated anomalies of observed ocean temperature and salinity in the upper $3000 \mathrm{~m}$ depth relative to the 19611990 climatology, by applying an incremental analysis update method [35]. Initial conditions on 1st January 1945 of these assimilation runs were taken from a 10-member ensemble of 1850-2000 historical climate changes simulations without assimilation (Figure 1) [36].

Mean responses to volcanic forcing can persist for only a few years after the eruption. On the other hand, perturbations or noises in the natural variability due to the volcanic forcing can grow with time in the chaotic climate system. These growing noises cause errors in predictions of the natural variability and thereby reduce the potential predictability. Here, we defined $V_{i}$ and $A_{i}$ as the climate variable in question of $i$ th members of experiments VOL and $\mathrm{A} 2$, respectively. The difference between them, $D_{i} \equiv$ $V_{i}-A_{i}$, includes both the mean response to volcanic forcing and noises in the natural variability. The ensemble average of $D_{i}, \bar{D}$, is the best estimate of the mean responses to forcing. Statistical significance of $\bar{D}$ was tested by $\pm 10 \% t$ test. Deviations of $V_{i}$ and $A_{i}$ from their ensemble means are denoted by $V_{i}^{\prime}$ and $A_{i}^{\prime}$, respectively. They are considered as the natural variability. If the volcanically induced noises in 


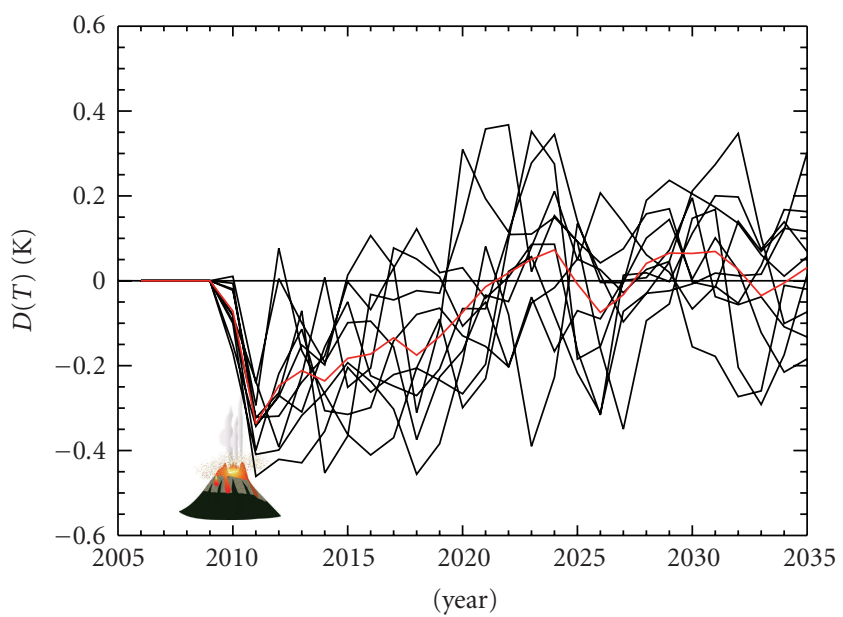

(a)

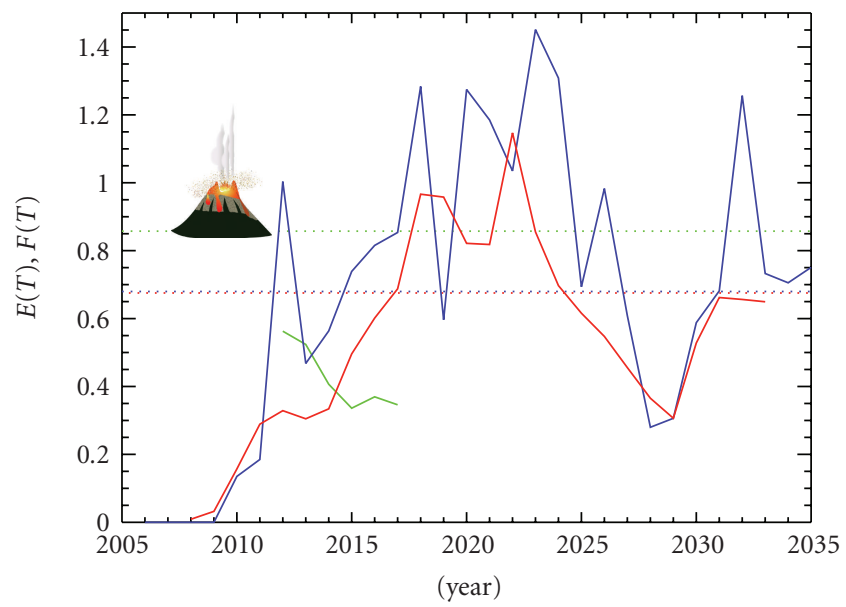

(c)

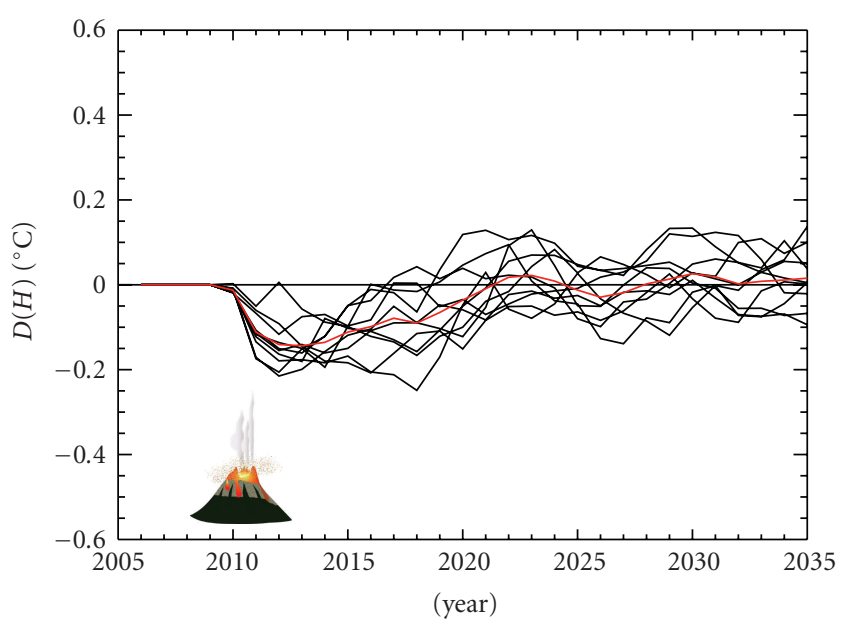

(b)

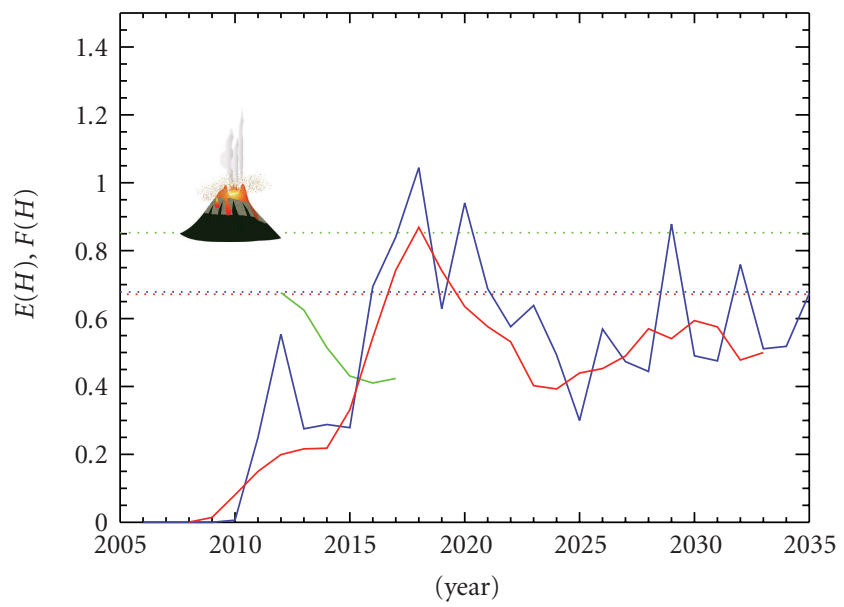

(d)

Figure 2: (a) Black and red lines indicate $D_{i}$ and $\bar{D}$ for the global mean $T$, respectively (K). (c) Blue and red lines show $E(T)$ for the annual mean and the 5-yr running mean $T$, respectively. Green line is $F(T)$ for the 5-yr running mean $T$ of the HIND runs, where the year 2010 means the 1st year of hindcast. Dotted lines denote the $10 \%$ significance levels of $F$-test. Right panels are the same as the left panels, except for the average ocean temperature in the upper $125 \mathrm{~m}(H)$.

the natural variability are small, $V_{i}^{\prime} \approx A_{i}^{\prime}$. To investigate possible influences of the volcanic forcing on the potential predictability of the natural variability, we examined the normalized ensemble variances $[12,13]$,

$$
E \equiv \sum_{i} \frac{\left(V_{i}^{\prime}-A_{i}^{\prime}\right)^{2}}{\left(9 \times 2 \times \sigma^{2}\right)}
$$

where $\sigma^{2}$ is the variance of a 3600 -year preindustrial control run (Figure 1). This is a measure of error growth in the natural variability. If $E<1$, the potential predictability of the natural variability is considered to persist. If $E=1$, it means that the volcanically induced error saturated, diminishing the potential predictability of the natural variability. We tested if $E<1$ at the $10 \%$ significance level of $F$-test. The degrees of freedom were assumed as $(9, n)$. Here $n$ is an effective sample size of the control run at each grid, estimated by considering the persistence in a first-order autoregression [37]. It should be noted that this method does not calculate predictability with imperfect knowledge of the initial states, but that with perfect knowledge of the initial states $\left(V_{i}^{\prime}=A_{i}^{\prime}\right.$ before the volcanic eruption) under external forcing perturbations. In other words, the results of the present study give an upper limit of predictability after the volcanic eruption.

Furthermore, we performed and examined another pair of 10-member ensembles, which were the same as VOL and A2, but ensembles without initializations based on data assimilation (the yellow ensembles in Figure 1). The results of these experiments (not shown) were similar to the results discussed below. It implies that our findings of volcanic effects did not depend on details of assimilation method and sampling.

If noises due to the volcanic forcing grow much slower than that arising from imperfect knowledge of the observed state in regions where our model has skills for predictions of the natural variability, unpredictable volcanic eruptions do 


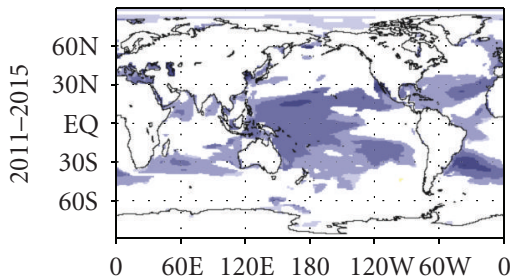

(a) $\bar{D}(H)$

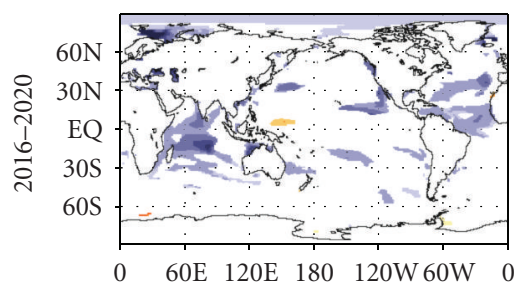

(b)

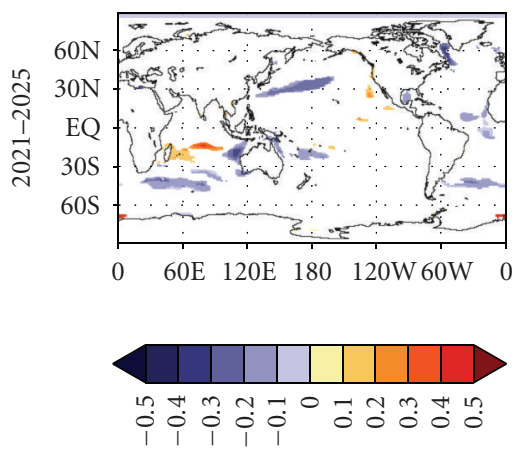

(c)

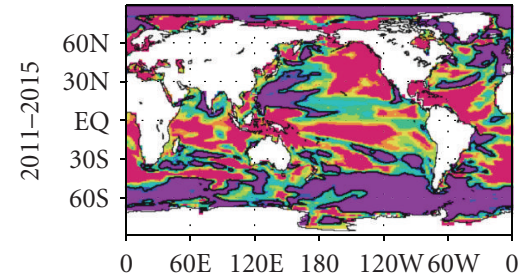

(d) $E(H)$

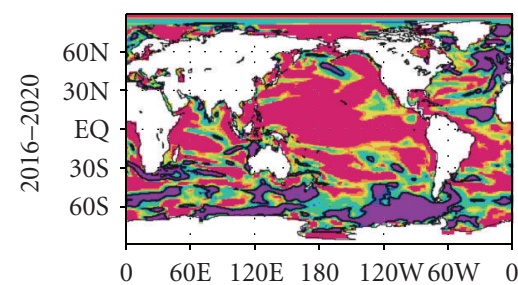

(e)

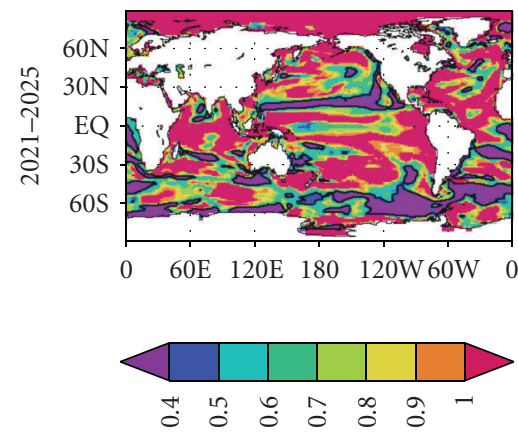

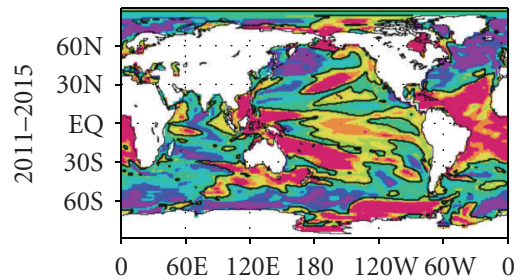

(g) $1-5 F(H)$
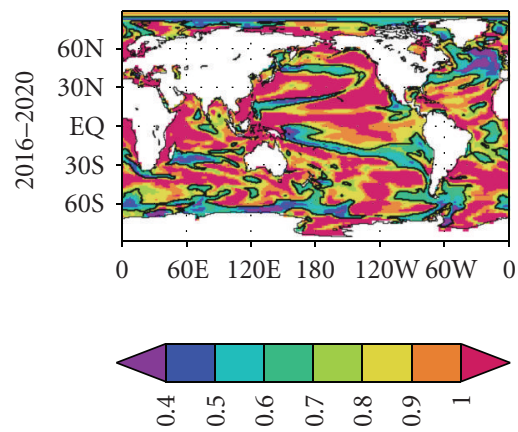

(h) 6-10

(f)

Figure 3: Geographical distributions of changes in 5-yr averaged $H$. Left panels are the mean responses to the Pinatubo forcing, $\bar{D}(H)$, from the 2011-2015 period to the 2021-2025 period $\left({ }^{\circ} \mathrm{C}\right)$. Shading shows only significant responses at the $\pm 10 \%$ levels of $t$-test. Middle and right panels indicate $E(H)$ and $F(H)$, respectively. Contours denote significant small $E(H)$ and $F(H)$ at the $10 \%$ level of $F$-test.

not largely affect our near-term predictions of the natural variability (in contrast, the volcanic forcing would affect the predictions of changes in the mean climate for a few years). To investigate errors in the predictions of the natural variability due to imperfect knowledge of the observed state, we performed five ensembles of 10-year-long hindcast (hereafter HIND) (Figure 1). Their ensemble sizes were 10. Initial conditions for these experiments were those at 1st January of 1961, 1976, 1981, 1986, and 1991 of the 10member assimilation runs. In the HIND runs, anthropogenic and natural forcing were the same as Nozawa et al. [36], but the volcanic forcing was held constant at the conditions of the year $1960,1975,1980,1985$, and 1990 . We defined $G(i, j)$ as the climate variable in question of $i$ th member of $j$ th HIND ensemble $(j=1, \ldots, 5) . G^{\prime}(i, j)$ is the $i$ th member's deviation from the ensemble mean of the $j$ th HIND ensemble. We examined normalized ensemble variances of the HIND runs,

$$
F \equiv \sum_{j} \sum_{i} \frac{G^{\prime}(i, j)^{2}}{\left(9 \times 5 \times \sigma^{2}\right)} .
$$

The degrees of freedom were assumed as $(45, n)$. By comparing $E$ and $F$, we investigated if errors due to volcanic forcing grew faster than that arising from imperfect knowledge of the observed state.

\section{Results}

At first, we investigated global mean time series of surface air temperature $(T)$ and vertically-averaged ocean temperature in the upper $125 \mathrm{~m}(H)$. The mean volcanic responses offset anthropogenic warming for several years (Figures 2 (a) and 2(b)). Whereas the cooling trends of $\bar{D}(T)$ and $\bar{D}(H)$ were recovered, noises in the natural variability grew with time, resulting in rapid increases of $E(T)$ and $E(H)$ beyond the significant level by the year 2017 (Figures 2(c) and 2(d)). It was suggested that the potential predictability of the global mean natural variability would soon diminish. On the other hand, errors due to different initial conditions, $F(T)$ and $F(H)$, kept lower than the significant level during the 10 years. Decline trends of $F(T)$ and $F(H)$ would be fluctuations due to finite sampling. 


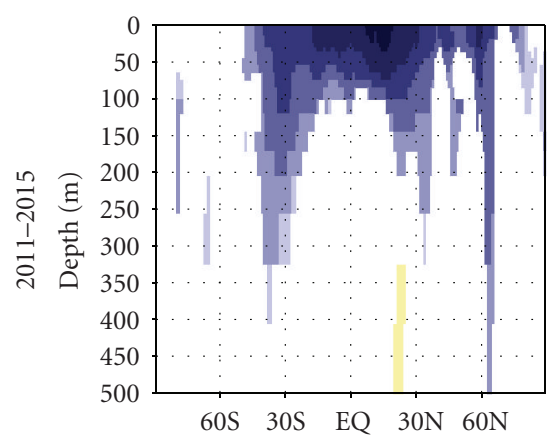

(a) $\bar{D}(T O)$

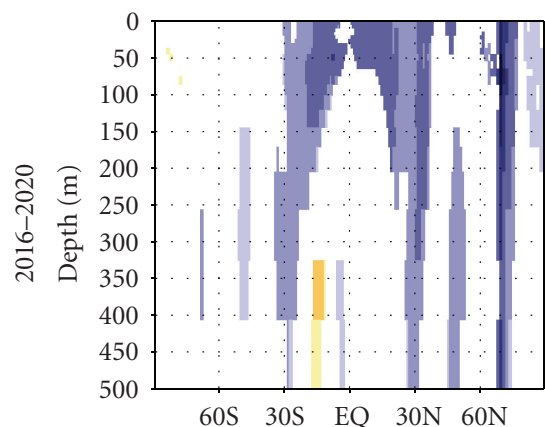

(b)

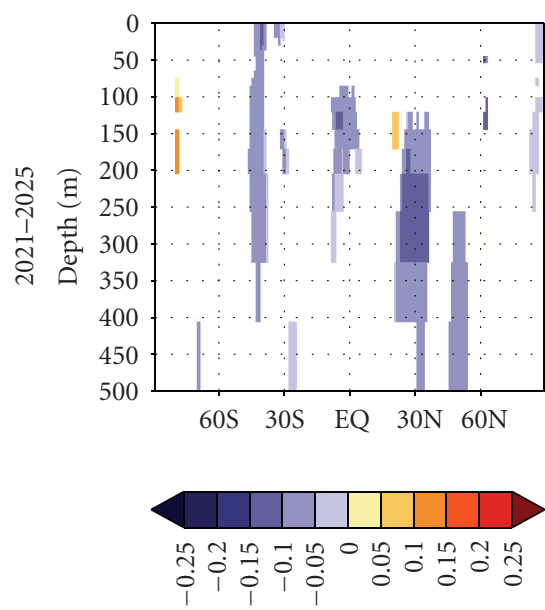

(c)

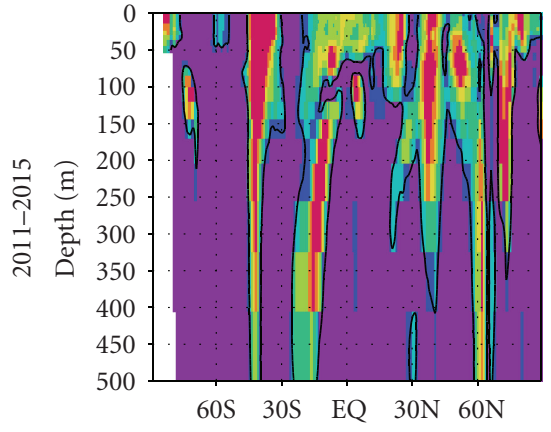

(d) $E(T O)$

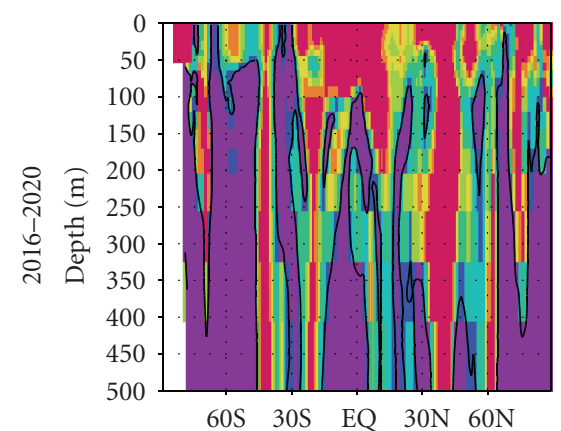

(e)

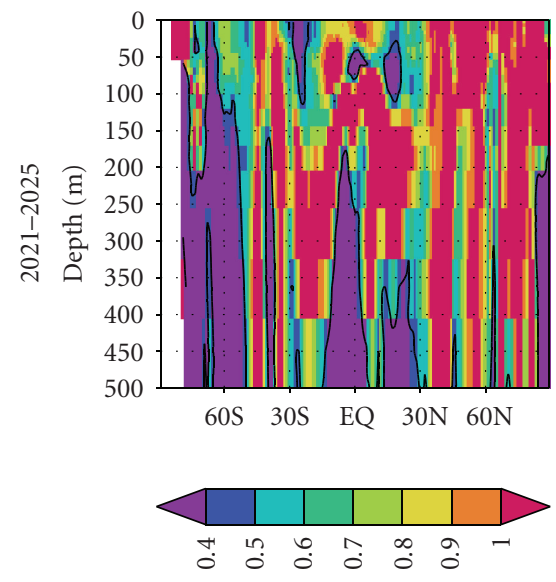

(f)

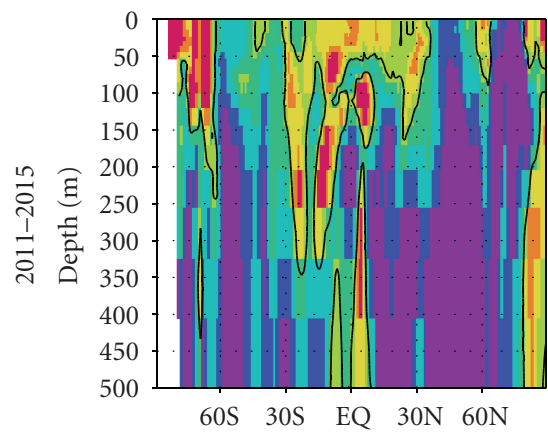

(g) $1-5 F(T O)$

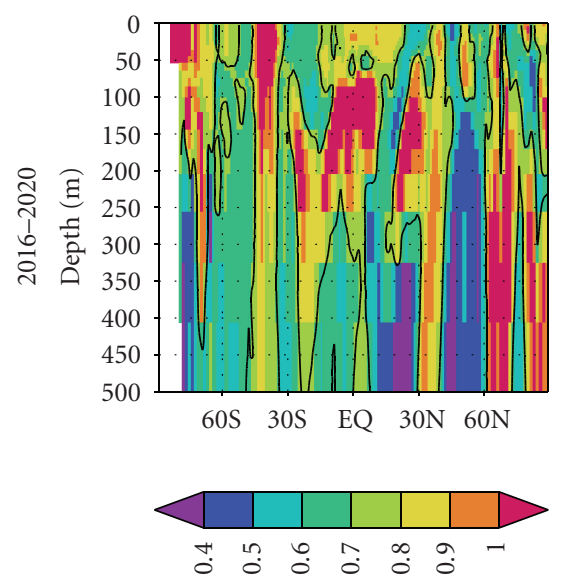

(h) 6-10

Figure 4: Changes in 5-yr averaged zonal mean TO. Left panels are the mean responses to the Pinatubo forcing, $\bar{D}(T O)$, from the 2011-2015 period to the 2021-2025 period $\left({ }^{\circ} \mathrm{C}\right)$. Shading shows only significant responses at the $\pm 10 \%$ levels of $t$-test. Middle and right panels indicate $E(T O)$ and $F(T O)$, respectively. Contours denote significant small $E(T O)$ and $F(T O)$ at the $10 \%$ level of $F$-test.

Figure 4 shows $\bar{D}, E$, and $F$ for the zonal 5 -year mean ocean temperature in the upper $500 \mathrm{~m}(\mathrm{TO})$. Initially, the Pinatubo forcing induced large cooling anomalies in the upper ocean in the extratropics of the Northern Hemisphere and the tropics. Initial growths of $E(T O)$ were found around the significant cooling responses. Potential predictability mostly disappeared by the year 2021 north of $45^{\circ} \mathrm{S}$. An interesting finding was that the initial $\bar{D}(T O)$ was small in the high latitudes of the Southern Hemisphere, and the potential predictability of the natural variability remained for decades. The lack of cooling in the high latitudes of the Southern Hemisphere may be due to the fact that heat transport from the Tropics into the high latitudes of the Southern Hemisphere is limited by the existence of the Antarctic circumpolar current. Small initial errors resulted in less error growth and hence the long persistence of the potential predictability of the natural variability. Patterns of $F(T O)$ were different from that of $E(T O)$. In the 1st 5year period, predictability remained in the extratropics of the Northern Hemisphere as well as the Southern Ocean. $F(T O)$ increased slower than $E(T O)$ in the 2nd 5-year period. 
Figure 3 shows the geographical distributions of $\bar{D}(H)$, $E(H)$, and $F(H)$. The Pinatubo forcing cooled the upper layers of the ocean in the tropics and subtropics, and $E(H)$ increased beyond the significant level north of $45^{\circ} \mathrm{S}$ during the 2011-2015 period. On the other hand, potential predictability persisted for a long time in the Southern Ocean. In the 1st 5-year period, $F(H)$ was smaller than $E(H)$ in many regions, except in the Southern Ocean. In the 2nd 5-year period, although $F(H)$ increased, potential predictability persisted along the ocean gyre circulation path in the North Pacific (i.e., along $40^{\circ} \mathrm{N}$ and $15^{\circ} \mathrm{N}$ ), where are key regions for predictions of the Pacific Decadal Oscillation (PDO) [21]. Mochizuki et al. [21] have shown that predictions of the PDO are important for that of the global mean temperature changes in the coming decade. Volcanically induced errors quickly diminished potential predictability of the PDO. In the Southern Ocean, $F(H)$ increased faster than $E(H)$. These rapid increases of $F(H)$ were probably caused by a large uncertainty of observations, since observations of ocean temperature and salinity were limited in the Southern Ocean.

\section{Summary and Discussion}

The present study examined whether the decadal predictability of the natural variability in near-term climate predictions could persist in spite of disturbances due to a repeat of the 1991 Mt. Pinatubo eruption in the year 2010. One may have guessed, without evidence, that unpredictable future volcanic activity could have a considerable influence on decadal predictions of the natural variability. We first confirmed this assumption. At least in the MIROC3 model, unpredictable future volcanic activity, like the $1991 \mathrm{Mt}$. Pinatubo eruption, led to rapid decreases of the potential predictability of the natural variability except in the Southern Ocean. Unfortunately, observation data of ocean temperature and salinity are limited in the Southern Ocean. Therefore, it may be difficult to expect that initialization based on assimilations of observed historical data over this region can effectively assist in the prediction of the decadal natural variability in near-term predictions.

If significant volcanic activity occurred in the near future, depositing a high concentration of sulfate aerosols into the stratosphere, the decadal predictions of the natural variability would be considerably affected. It is not easy to do reinitialization, since the decadal prediction requires huge computational costs. However, to inform climate adaptation policy, our recommendation is to perform predictions again if any large volcanic eruptions occur. If the climate research community established systems of operational decadal prediction or performed near-term predictions at an interval of about 5 years, which is the typical interval of internationally coordinated climate change experiments, the problems due to unpredictable natural forcing would be limited.

We investigated the responses of the climate to the Pinatubo forcing. Climate responses to large volcanic eruptions are dependent on the magnitude and location of the volcanic eruption [38]. Furthermore, the model uncertainty of the responses to the volcanic forcing is not small in current AOGCMs [29]. Stenchikov et al. [29] suggested that the current AOGCMs might overestimate the cooling of sea surface temperature after eruptions when compared to observations. Therefore, our estimates of volcanic influence may be somewhat overestimated. Further studies would be clearly worthwhile.

\section{Acknowledgments}

The authors thank two reviewers and E. Rozanov for their useful comments. They also thank A. Yamada, S. Toyoshima, and N. T. Edit for their supports. This work was supported by the Innovative Program of Climate Change Projection for the 21st Century for Scientific Research from the Ministry of Education, Culture, Sports, Science and Technology of Japan and by the Global Environment Research Fund (S5) of the Ministry of the Environment of Japan. The Earth Simulator at JAMSTEC and an NEC SX-8R at NIES were used to perform the AOGCM simulations.

\section{References}

[1] K. A. Hibbard, G. A. Meehl, P. M. Cox, and P. Friedlingstein, "A strategy for climate change stabilization experiments," EOS, Transactions, American Geophysical Union, vol. 88, no. 20, pp. 217-219, 2007.

[2] G. A. Meehl and K. Hibbard, "A strategy for climate change stabilization experiments with AOGCMs and ESMs," Summary Report of Aspen Global Change Institute Session. Earth System Models. The Next Generation, AGCI, 2006.

[3] P. Cox and D. Stephenson, "A changing climate for prediction," Science, vol. 317, no. 5835, pp. 207-208, 2007.

[4] Intergovernmental Panel on Climate Change (IPCC), "Towards new scenarios for analysis of emissions, climate change, impacts, and response strategies," in Proceedings of the 28th Session on the Intergovernmental Panel on Climate Change (IPCC '08), Budapest, Hungary, April 2008.

[5] G. A. Meehl, L. Goddard, J. Murphy et al., "Decadal prediction: can it be skillful?" Bulletin of the American Meteorological Society, vol. 90, no. 10, pp. 1467-1485, 2009.

[6] P. A. Stott and J. A. Kettleborough, "Origins and estimates of uncertainty in predictions of twenty-first century temperature rise," Nature, vol. 416, no. 6882, pp. 723-726, 2002.

[7] R. Knutti, T. F. Stocker, F. Joos, and G.-K. Plattner, "Constraints on radiative forcing and future climate change from observations and climate model ensembles," Nature, vol. 416, no. 6882, pp. 719-723, 2002.

[8] F. W. Zwiers, "Climate change: the 20-year forecast," Nature, vol. 416, no. 6882, pp. 690-691, 2002.

[9] E. Hawkins and R. Sutton, "The potential to narrow uncertainty in regional climate predictions," Bulletin of the American Meteorological Society, vol. 90, no. 8, pp. 1095-1107, 2009.

[10] H. Shiogama, T. Nozawa, and S. Emori, "Robustness of climate change signals in near term predictions up to the year 2030: changes in the frequency of temperature extremes," Geophysical Research Letters, vol. 34, no. 12, article L12714, 5 pages, 2007.

[11] H. Shiogama, A. Hasegawa, T. Nozawa, and S. Emori, "Changes in mean and extreme precipitation in near-term 
predictions up to the year 2030," Scientific Online Letters on the Atmosphere, vol. 4, pp. 17-20, 2008.

[12] S. M. Griffies and K. Bryan, "Predictability of North Atlantic multidecadal climate variability," Science, vol. 275, no. 5297, pp. 181-184, 1997.

[13] S. M. Griffies and K. Bryan, "A predictability study of simulated North Atlantic multidecadal variability," Climate Dynamics, vol. 13, no. 7-8, pp. 459-487, 1997.

[14] G. J. Boer, "A study of atmosphere-ocean predictability on long time scales," Climate Dynamics, vol. 23, no. 1, pp. 29-44, 2000.

[15] M. Collins, "Climate predictability on interannual to decadal time scales: the initial value problem," Climate Dynamics, vol. 19, no. 8, pp. 671-692, 2002.

[16] H. Pohlmann, M. Botzet, M. Latif, A. Roesch, M. Wild, and P. Tschuck, "Estimating the decadal predictability of a coupled AOGCM," Journal of Climate, vol. 17, no. 22, pp. 4463-4472, 2004.

[17] H. Pohlmann, J. H. Jungclaus, A. Köhl, D. Stammer, and J. Marotzke, "Initializing decadal climate predictions with the GECCO oceanic synthesis: effects on the North Atlantic," Journal of Climate, vol. 22, no. 14, pp. 3926-3938, 2009.

[18] D. M. Smith, S. Cusack, A. W. Colman, C. K. Folland, G, R. Harris, and J. M. Murphy, "Improved surface temperature prediction for the coming decade from a global climate model," Science, vol. 317, no. 5839, pp. 796-799, 2007.

[19] A. Troccoli and T. N. Palmer, "Ensemble decadal predictions from analysed initial conditions," Philosophical Transactions of the Royal Society A, vol. 365, no. 1857, pp. 2179-2191, 2007.

[20] N. S. Keenlyside, M. Latif, J. Jungclaus, L. Kornblueh, and E. Roeckner, "Advancing decadal-scale climate prediction in the North Atlantic sector," Nature, vol. 453, no. 7191, pp. 84-87, 2008.

[21] T. Mochizuki, M. Ishii, M. Kimoto et al., "Pacific decadal oscillation hindcasts relevant to near-term climate prediction," Proceedings of the National Academy of Sciences of the United States of America, vol. 107, no. 5, pp. 1833-1837, 2010.

[22] W. T. Hyde and T. J. Crowley, "Probability of future climatically significant volcanic eruptions," Journal of Climate, vol. 13, no. 9, pp. 1445-1450, 2000.

[23] C. Bertrand, J.-P. Van Ypersele, and A. Berger, "Are natural climate forcings able to counteract the projected anthropogenic global warming?" Climatic Change, vol. 55, no. 4, pp. 413-427, 2002.

[24] A. Robock, "Volcanic eruptions and climate," Reviews of Geophysics, vol. 38, no. 2, pp. 191-219, 2000.

[25] J. A. Church, N. J. White, and J. M. Arblaster, "Significant decadal-scale impact of volcanic eruptions on sea level and ocean heat content," Nature, vol. 438, no. 7064, pp. 74-77, 2005.

[26] P. J. Gleckler, T. M. L. Wigley, B. D. Santer, J. M. Gregory, K. AchutaRao, and K. E. Taylor, "Krakatoa's signature persists in the ocean," Nature, vol. 439, no. 7077, p. 675, 2006.

[27] P. J. Gleckler, K. AchutaRao, J. M. Gregory, B. D. Santer, K. E. Taylor, and T. M. L. Wigley, "Krakatoa lives: the effect of volcanic eruptions on ocean heat content and thermal expansion," Geophysical Research Letters, vol. 33, no. 17, article L17702, 5 pages, 2006.

[28] G. Stenchikov, A. Robock, V. Ramaswamy, M. D. Schwarzkopf, K. Hamilton, and S. Ramachandran, "Arctic oscillation response to the 1991 Mount Pinatubo eruption: effects of volcanic aerosols and ozone depletion," Journal of Geophysical Research D, vol. 107, no. 24, article 4803, 2002.

[29] G. Stenchikov, K. Hamilton, R. J. Stouffer et al., "Arctic oscillation response to volcanic eruptions in the IPCC AR4 climate models," Journal of Geophysical Research, vol. 111, article D07107, 17 pages, 2006.

[30] K-1 Model Developers, "K-1 coupled GCM (MIROC) description," H. Hasumi and S. Emori, Eds., p. 34, Center For Climate System. Research, University of Tokyo, Tokyo, Japan, 2004.

[31] T. Yokohata, S. Emori, T. Nozawa, Y. Tsushima, T. Ogura, and M. Kimoto, "Climate response to volcanic forcing: validation of climate sensitivity of a coupled atmosphere-ocean general circulation model," Geophysical Research Letters, vol. 32, no. 21, article L21710, 5 pages, 2005.

[32] H. Shiogama, T. Nagashima, T. Yokohata, S. A. Crooks, and T. Nozawa, "Influence of volcanic activity and changes in solar irradiance on surface air temperatures in the early twentieth century," Geophysical Research Letters, vol. 33, no. 9, article L09702, 4 pages, 2006.

[33] N. Nakicenovic, J. Alcamo, G. Davis, et al., Emissions Scenarios. A Special Report of Working Group III of the Intergovernmental Panel on Climate Change, Cambridge University Press, New York, NY, USA, 2000.

[34] M. Sato, J. E. Hansen, M. P. McCormick, and J. B. Pollack, "Stratospheric aerosol optical depths, 1850-1990," Journal of Geophysical Research D, vol. 98, no. 12, pp. 22987-22994, 1993.

[35] S. C. Bloom, L. L. Takacs, A. M. Da Silva, and D. Ledvina, "Data assimilation using incremental analysis updates," Monthly Weather Review, vol. 124, no. 6, pp. 1256-1271, 1996.

[36] T. Nozawa, T. Nagashima, H. Shiogama, and S. A. Crooks, "Detecting natural influence on surface air temperature change in the early twentieth century," Geophysical Research Letters, vol. 32, no. 20, article L20719, 4 pages, 2005.

[37] D. S. Wilks, Statistical Methods in the Atmospheric Sciences, Academic Press, New York, NY, USA, 1995.

[38] L. Oman, A. Robock, G. Stenchikov, G. A. Schmidt, and R. Ruedy, "Climatic response to high-latitude volcanic eruptions," Journal of Geophysical Research D, vol. 110, article D13103, 13 pages, 2005. 

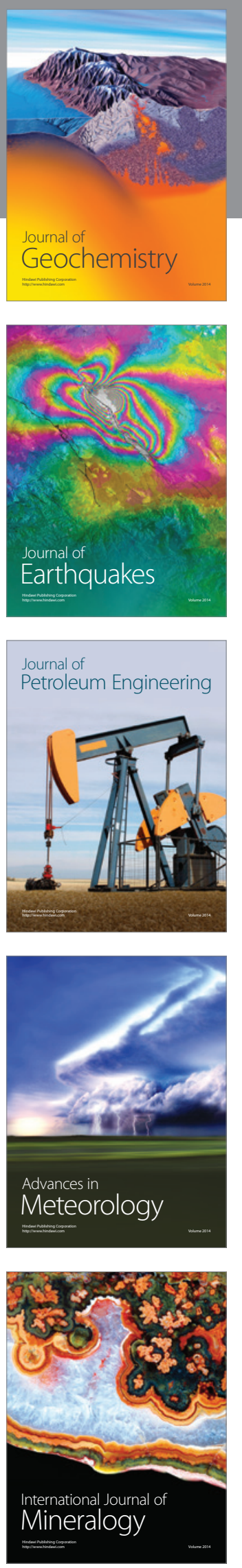
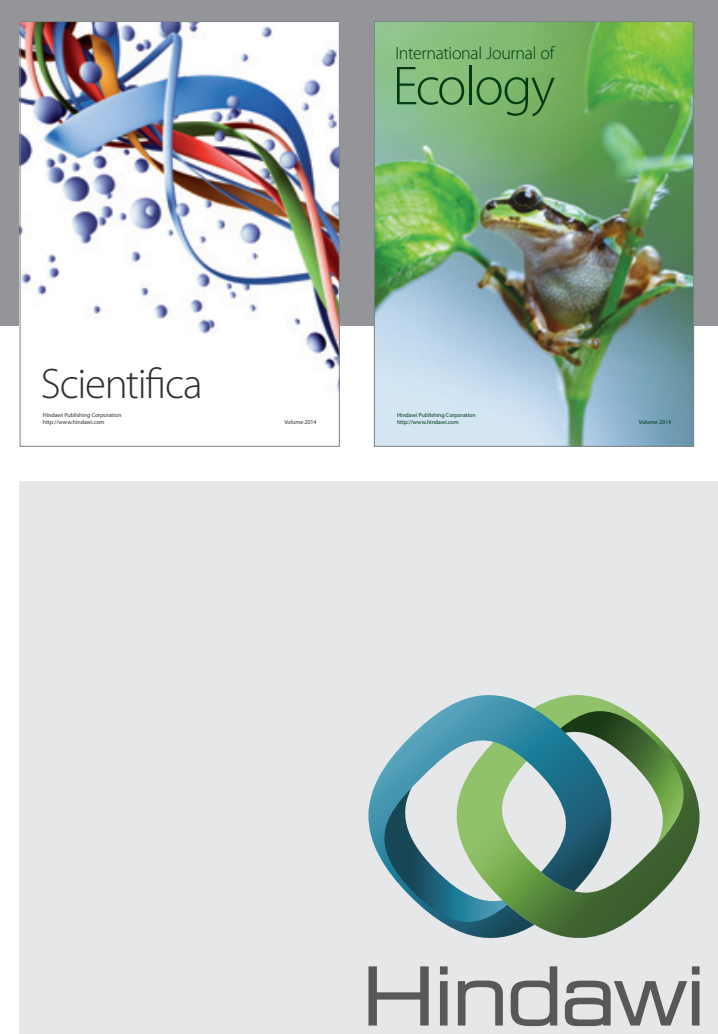

Submit your manuscripts at http://www.hindawi.com
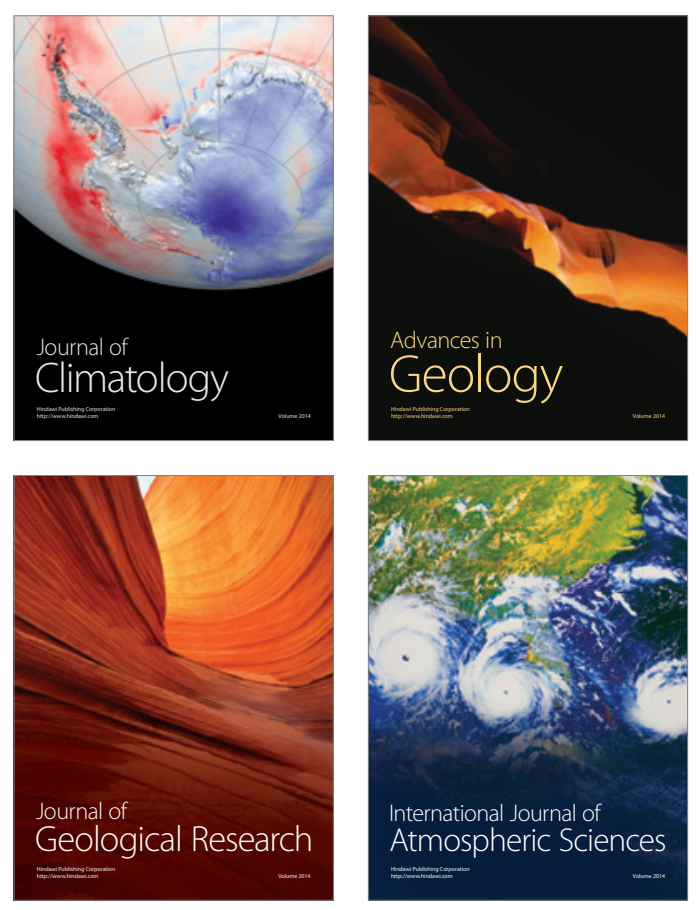
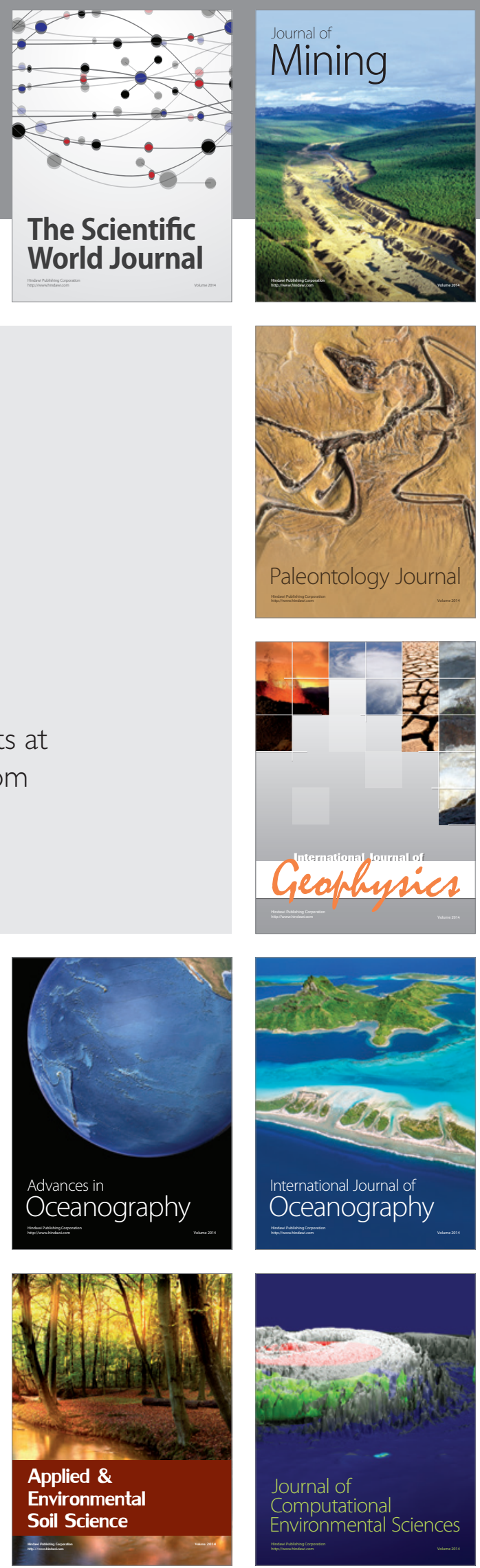